\title{
PSYCHOLOGICAL COUNSELING AS A NEW INNOVATION AND PRACTICE IN HIGHER EDUCATION INSTITUTIONS IN ALBANIA
}

Rudina Shkulaku, European University of Tirana, rudina.shkullaku@uet.edu.al

Maintaining a best possible qualitative service and student's wellbeing, in the higher education institutions (HEI), is particularly important. The focal scope of this research is to present the importance of the integration of the psychological counseling service in the HEI in Albania. The methodology was a comparative analysis of the models of Psychological counseling service in HEI of Europe and Albania. Two main results of the study are: First, the monitoring process of thirty-five Albanian university/college websites showed that only five of them have integrated psychological counseling services into their systems. Second, $72 \%$ of the students said that their university didn't provide psychological counseling service. $94.8 \%$ of them would like their university to provide this kind of service. The few universities that offer this service have just introduced formal psychological counseling in recent years, which shows that this service is still in the beginning steps.

UDC Number: 159.9, DOI: 10.12955/cbup.2013.38

Key words: psychological counseling, wellbeing of student, quality of service, student stress

\section{Introduction}

Education is a precious human benefit and every citizen can enjoy the right for education. According to Efklides (2011) higher education enables graduates a better financial situation, better social status, equal social participation, personal development and better living conditions generally. Institutions of Higher Education carry in itself a very important mission and educational research. Their main purpose is to produce and transmit scientific knowledge and to train subjects to transmit this knowledge to other individuals.

While there have been taken many steps for the expansion of higher education, Albania has just started to give importance to the quality of services that these institutions, private and public provide. Most of them consider the welfare of the students as one of the most important strategic goals. Knight (2006) found that institutions that show particular attention to the psycho-emotional well-being of student are considered higher quality educational service institutions and are of high value to the student. When the students begin their studies at an institution of higher learning, it is a transitional period, in which students face different situations and different lifestyles.

As determined by Kalantzi-Azizi (2009), some of the challenges students face are: difficulties of adapting to a new physical and social environment; difficulties in time management; failure of not achieving high results against their expectations; lack of ability to concentrate; difficult family 
situations; identity crises associated with depression; low self-esteem; difficulty in their communication with the professors, staff and peers; fear and lack of skills to manage the future. This is a time when they particularly need support to meet the challenges and demands of a university/college successfully. In this way psychological counseling will take a special significance.

While students will be faced with all the difficulties that I mentioned above, it makes many of them to see and experience a stressful period at university/college. According to Feltham \& Dryden (2010), if these factors are not shared and managed successfully, the lack of effectiveness in personal and academic life will accompany the students for a long time during their lives.

The legal framework for undergraduate studies in the world and in Albania provides the provision of this service as a necessity for the preservation and care of a young adult's mental health. Integration of psychological counseling in higher education should be interpreted as an imperative that consolidates the activities of the institution as a whole. Psychology makes a very important contribution to the prevention, mitigation or resolution of a set of challenges and problems that affect the lives of students, not only within the organization but also outside it.

\section{Being a student and the dilemmas that can be resolved through psychological counseling}

Described by Arnett (2010), generally students who belong to the age group 18-25, are part of a transition-oriented group-Early Adolescence to Adulthood. During this period, they are in the process of consolidating their identity, especially when they have to deal with the transition of moving from family to a new social environment and educational system. Stated by Margolis (1981), separation from the family environment as well as separation from their previous social environment, leaves deep impressions on the future development of an individual. Often loneliness and low family support can interact with other difficult conditions and lead to the experience of depressive conditions of the students. Concluded by Lago (2002), stress, anxiety, depression, suicidal thoughts, sexual problems and personality disorders, represent some of the most common problems that the students face.

\section{Psychological counseling's role within and outside the academic life of students}

The main goal of higher education institutions, when integrating a psychological counseling center into their structure, is to try to cover a wide range of student requirements. Since 1965 counseling psychologists have claimed that the main reason of the application of psychological counseling is related to certain clients' need for professional help. Higher education institutions want people oriented and trained to solve problems which they are not able to solve themselves.

As said by Bonner \& Rich (1992), various scientific research in this field has shown that better problem-solving skills are often closely related to the self-concept, self-esteem individuals, with low levels of anxiety and depression, pessimism and suicidal tendencies, the possession of good social skills, as well as possessing good endurance skills. The focus of psychological counseling at a university/college is to affirm emotional and psychological support of students in order to help them adjust more easily and timely to the difficulties related to the new education system, as well as to enable them to find more effective solutions to the problems that they might have. All this is achieved by focusing on their optimal potential, promoting self-fulfillment, psychological and emotional wellbeing. 


\section{Psychological counseling service in the best five Higher Education Institutions in Europe: Models for us to follow}

As stated by Rott (2006), the necessity of opening psychological counseling centers in higher education institutions is already known by the whole community of psychologists as a very important factor, not only for academic success but also for personal development, growth and the welfare of the students. Times Higher Education World University Rankings" (2011-2012), the authority recognized globally for classification of higher education institutions, rated five universities as the best worldwide: University of Oxford, UK; University of Cambridge, UK; Imperial College of London, UK; ETH Zurich - Swiss Federal Institute of Technology Zurich, Switzerland; and the University College of London, UK.

These five institutions have integrated into their structures the psychological counseling service by offering individual counseling, group counseling, seminars, workshops, self-help resources, counseling "peer to peer". All these forms of counseling are available to all students and special counseling programs are offered also for the academic staff, depending on their needs. In some of the universities/colleges this service is available 24 hours.

Likewise, if we refer to the history of psychological counseling in one of the neighboring countries like Greece, we will see that since the '90s, Institutions of Higher Education are progressively aware of the provision of this service as an opportunity to prevent problems or to facilitate coping with difficulties. The first psychological counseling center in Greece was opened at the University of Athens. The university has also continued to provide guidance and encouragement for the foundation of psychological counseling services at other universities/colleges in Greece.

According to the study done by the University of Macedonia in Thessaloniki, Greece -Evaluation of Psychological Counseling Services in Higher Education (2009) identified, during their assessment on the provision of counseling services, attractive topics for students were: building interpersonal relationships, avoiding loneliness, building self-esteem, improving social skills, improving academic performance, stress and anger management skills, handling panic disorders, issues related to sexuality, avoiding substance abuse.

Some of the most important psychological counseling services offered by these universities are individual counseling, group counseling and various workshops that address some of the above mentioned topics. Reference to the patterns of the countries that have greater similarity in terms of socio-economic status and cultural development of our country is a positive step in embracing new initiatives.

\section{Foreign university psychological counseling, facts and ratings}

Described by Rott (2006), previous experiences in the higher education community worldwide have shown that psychological counseling centers provide more useful services for students and more developments in theoretical thinking and scientific research. Currently, student psychological counseling is already a service developed in practice by creating the concept of practical psychology. A series of data demonstrates an increased level of concern for mental health and emotional overload of students. Rickinson and Rutherford (1998) studied the effectiveness of counseling interventions in two transition points: the first year of the university/college and the graduation year. For both groups of students, it was noticed that their retention base was influenced by their capacity to adapt to 
inevitable processes caused by being part of a university/college. Students who participated in counseling sessions were better at managing the challenges of university/college life.

Manthorpe and Stanley in 1999 observed and came to the conclusion that awareness and acceptance of psychological counseling services by the students is the key in dealing with emotional and psychological pressure and other difficulties that the students face. A study at Brunel University done by their Counseling Evaluation Center (Caleb, 2002), noted that students were only facing $10 \%$ of their problems before counseling. However, after students received counseling, they were dealing with $50 \%$ of their problems. Over $80 \%$ of the students who participated in the study commented that counseling had helped them to improve their academic performance and achievement. Thanks to this detailed and critical framework, Ross and Taylor (2002), noted the importance of providing psychological counseling along with increasing academic support and better teaching conditions.

\section{Knowledge in theory and practice of psychological counseling in higher education in Albania}

The profession of a psychological counselor in Albania is new and currently is only legally recognized as a process for university education. We already know that the problems of education and school's effectiveness have their difficulties. Its solution requires knowledge and coordinating of all the work of everyone involved and especially the contribution of psychological counselors. Psychological counselors maintain direct relationships with students, teachers and the community by practicing the psychological approaches to social and emotional support to students in the school environment.

\section{Method and Participants}

The methodology of this scientific research paper is based on the monitory of 35 private and public university websites in Albania concerning the inclusion of psychological counseling into their structure, as well as on the application of an exploratory survey with 54 students at random sampling, 9 students per six main universities in the capital, 3 students per each academic year. The questionnaire was distributed to 34 female and 21 male students.

\section{Results and discussion}

During the monitoring of thirty-five Albanian university/college websites showed that only five of them have integrated psychological counseling services into their systems. The universities that offer this service have just introduced psychological counseling in recent years, which shows that this service is still in the beginning. Nevertheless, it still lacks genuine studies to evaluate the performance of this service. Universities/colleges that do not offer this service are more focused on providing academic counseling and career development counseling. The questionnaire results are shown in the Table 1.

Concerning the open question on the identification of the problems you would go to the university psychological counselor, the students listed as main problems: problems with their sleep, financial difficulties, time management, development of the feeling of independence from their family, post university uncertainties, family and society related conflicts, stress management, difficulties with adapting themselves to the new physical and social university environment. 
Table 1: Percentage of responses on the inclusion of psychological counseling in higher education

\begin{tabular}{|c|c|l|c|c|c|}
\hline No. & \multicolumn{1}{|c|}{ Questions } & Yes & No & Do not know \\
\hline 1 & $\begin{array}{l}\text { Do you know the psychological } \\
\text { counseling at the university? }\end{array}$ & $75.9 \%$ & $24 \%$ & $0 \%$ \\
\hline & $\begin{array}{l}\text { Does your university provide } \\
\text { psychological counseling service? }\end{array}$ & $11.1 \%$ & $72.2 \%$ & $16.6 \%$ \\
\hline & If it does, has it been helpful to you? & $66.6 \%$ & $0 \%$ & $33.3 \%$ \\
\hline 3 & $\begin{array}{l}\text { If it does not, would you like your } \\
\text { university to provide this kind of service? }\end{array}$ & $94.8 \%$ & $0 \%$ & $5.1 \%$ \\
\hline
\end{tabular}

Source: Author

\section{Conclusion}

Psychological counseling not only works to provide academic growth, but also provides a qualitative service for students in contributions in making personal difficulties easier, as well as academic growth and psycho-emotional welfare. The findings above are indicators of the necessity of having this service in Institutions of Higher Education. Based on the social conditions, background, missing information and the mentality of Albania, the inclusion of this service in the Institutions of Higher Education will be a challenge that requires a serious commitment of all of those that are serious in providing a better education for the students. The service of psychological counseling is a necessary standard for all Institutions of Higher Education.

\section{References}

Arnett, J. J. (2010). Adolescence and Emerging Adulthood: A Cultural Approach. (4th Edition). Boston, MA: Pearson.

Association of University and College Counsellors. (2002). Annual Survey of Counseling in Higher Education 2000-2001. Retrieved from http://www.hucs.org/retention.htm

Caleb, R. (2002). Evaluation Study. London, UK: Brunel University Press.

Charila, D. (1997). The students' Counseling Center of the University of Athens: first experiences (1990-1996). In Kalantzi-Azizi, A. (Ed.). Students' Psychological Counseling: Europe a perspective, Greek experience. (pp. 99-111). Athens, Greece: Ellinika Grammata - Fedora Psyche.

Efklides, A. (2011). Interactions of Metacognition with Motivation and Affect in Self-Regulated Learning: The MASRL Model School of Psychology. Thessaloniki, Greece: Aristotle University of Thessaloniki.

Feltham, C. \& Dryden, W. (2010). Brief Counselling A practical integrative approach. London, UK: Open University Press, Mc Graw Hill Education. PMCid:PMC2878517 
Knight, J. (2006). Guide to the Implications of the General Agreement of Trade in Services for Crossborder Education. A Report Prepared for the Commonwealth of Learning ED-2006/WS/61. Paris, France: UNESCO.

Lago, C. (2002). The University and the wider community. In Stanley, N. \& Manthorpe, J.

(Eds.). Students' Mental Health Needs - Problems and Responses. London, England: Jessica Kingsley.

Manthorpe, J. \& Stanley, N. (1999). Dilemmas in Professional Education: Responding Effectively to Students with Mental Health Problems. Journal of Inter professional Care. 3 (4), 355-365.

http://dx.doi.org/10.3109/13561829909010381

Reuters, T. (2011-2012). The World University Rankings. Retrieved from

http://www.timeshighereducation.co.uk/world-university-rankings/2011-12/world-

ranking/region/europe

Rickinson, B. \& Rutherford, D. (1996). Systematic Monitoring of the Adjustment to University of Undergraduates. British Journal of Guidance and Counselling, 24, 213 - 225.

Rickinson, B. \& Rutherford, D. (1998). The Relationship Between Undergraduate Student Counselling and Successful Degree Completion. Studies in Higher Education, 23, 95-102.

http://dx.doi.org/10.1080/03075079812331380522

Roberts, R. \& Zelenyanszki, C. (2002). Degrees of debt. In Stanley, N. \& Manthorpe, J.

(Eds.). Students' Mental Health Needs - Problems and Responses. London, England: Jessica Kingsley.

Ross, P. J. \& Taylor, A. M. (2002). Enhancing learning skills. In Dryden, W., McLeod, J. \& Strawbridge, S. (Eds.). Handbook of Counseling Psychology. London, UK: Sage Publications. Retrieved from http://www.hucs.org/retention.htm

Rott, G. (2006). The globalization in the Higher Education: Challenges and opportunities for Practicing Psychological Counseling. Epitheóriss Symvouleftikís - Prosanatolismoú [Review of Counseling and Guidance], 76-77, 118-129.

Survey into Medical, Psychiatric and Counseling Provision in Higher Education. (2002) Retrieved from http:/www.hucs.org 